\title{
Looking into the issues of rewards and punishment in students
}

Ching, Gregory S. $\bowtie$

Lunghwa University of Science and Technology, Taiwan, ROC (gregory_ching@yahoo.com)

Received: 9 December 2012

Revised: 15 January 2012

DOI: 10.5861/ijrsp.2012.v1i2.44

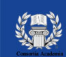

ISSN: $2243-7681$

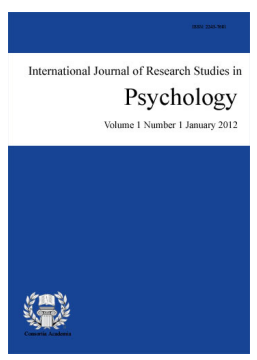

Online ISSN: 2243-769X

OPEN ACCESS

\section{Abstract}

A good classroom condition is one of the important aspects in classroom instruction. Many scholars had mentioned that learning is achieved when the students are well motivated. Similarly, different schools have different types of reward and penalty policy, but almost all of them have one common goal which is to motivate students to learn. Similarly, educators nowadays are aware that giving penalties are counterproductive. An effective rewards and penalty system should promote positive behavior and regular attendance, which are essential foundations to a creative learning and teaching environment. This study is concerned with the way in which rewards and penalties, may or may not, motivate students to engage in learning and change their behavior. This study also aims to explore the characteristics of systems of rewards and sanctions in four schools in the Philippines, and students' perceptions of the effectiveness of systems currently in use. Participants were graduating high school and college freshmen students of Chinese ethnicity. Questionnaires, interviews and observations were used to collect information regarding the students' engagement with learning, social control, and rewards and penalties policies. Results showed that although school policies tended to link their rewards and penalties system with a positive discipline approach the emphasis in practice often appeared to be on penalties for bad behavior rather than enhancing engagement and motivation. Students tended to perceive rewards to be strongly linked to work and penalties to behavior.

Keywords: motivation; learning attitudes; student performance; student behavior; learning styles 


\section{Looking into the issues of rewards and punishment in students}

\section{Introduction}

A good classroom condition is one of the most important aspects in classroom instruction (Beresford, 2000). Learning is achieved if the students are well motivated. Hence, motivation to learn is paramount to student success; however the source of motivation is somewhat complex (Boekaerts, 2002). Many has mentioned that rewards whether intrinsic or extrinsic stimulated new insights in some instances, and in other instances reaffirmed earlier research on achievement motivation in the McClelland-Atkinson tradition (McClelland, Atkinson, Clark, \& Lowell, 1976). McClelland and Atkinson demonstrated that motivation to choose, act, or persevere in an activity depended upon the relative expected value of possible goals in a situation and the expectancies of the probability that a given course of action would achieve the goal. When a student is well rewarded for the achievements done in class; this performance-mastery distinction has proved to be useful with regard to differences in goals that were lumped together in need achievement research. An example of reaffirmation of earlier work is the research on performance-avoidant students who demonstrated the same behavior as those labeled high fear of failure in the McClelland-Atkinson tradition (Atkinson, 1957; McClelland, 1958).

Currently, schools have different types of reward and penalty policy in placed, but almost all of them have one common goal which is to motivate students to learn. Educators nowadays are aware that giving penalties are counterproductive. Punishment tends to generate anger, defiance, and a desire for revenge. Moreover, it also gives example to the use of authority rather than reason and encouragement, thus this would tend to rupture the important relationship between adult and child (Kohn, 1994). An effective rewards and penalty system promotes positive behavior and regular attendance. It is the essential foundation for a creative learning and teaching environment.

Many educators and researchers have very different views on the effects of rewards (Walker, Colvin, \& Ramsey, 1995). One such is that there is no inherent negative property of rewards (Cameron, 2001). To Cameron (2001) obtaining a negative effect on reward requires an unusual combination of conditions which is not the actual real classroom settings. This can mean that teacher can use rewards to let her students achieve a better learning motivation, while according to Deci, Koestner, \& Ryan (2001) rewards do not increase a student intrinsic motivation to learn.

The ability of students to engage in learning is an equally important factor in their development as learners. Researchers have acknowledged the preparation of teaching as a key classroom condition for improving teaching and learning in schools, it is argued that the ability of students to organize their own learning is a complementary skill which needs to be addressed by teachers (Burnett, 2002). In the classroom teacher has become one of a burgeoning number of knowledge sources, students need to develop a battery of independent learning and problem-solving skills and techniques in order to process and learn from the wide information base now available (Shi, 2005). They need to develop and refine their own learning strategies in order that they can benefit fully from the variety of learning situations which they meet as students (McWhaw \& Abrami, 2001). However, still s major concern in educational settings is that the use of rewards and incentives may destroy students' intrinsic motivation to perform activities (Cameron, 2001). It is important to take note of the students' ethnicity, for they might be disparities in the culture acceptance towards motivation to learn (Chan \& Ma, 2004).

This study is concerned with the way in which rewards and penalties, may or may not, motivate students to engage in learning and change their behavior. This study also aims to explore the characteristics of systems of rewards and sanctions in four schools in the Philippines, and students' perceptions of the effectiveness of systems currently in use. Participants were graduating high school and college freshmen students of Chinese 
ethnicity. Questionnaires, interviews and observations were used to collect information regarding the students' engagement with learning, social control, and rewards and penalties policies.

\section{Background literature review}

\subsection{Education in the Philippines}

Philippine education is patterned after the American system, with English as the medium of instruction. Schools are classified into public (government) or private (non-government). The general pattern of formal education follows four stages: Pre-primary level (nursery and kindergarten) offered in most private schools; six years of primary education, followed by four years of secondary education (DepEd, 2007a). College education usually takes four, sometimes five and in some cases as in medical and law schools, as long as eight years (Ched, 2007). Graduate schooling is an additional two or more years (DepEd, 2007b). While some opted to study short termed two year vocational courses, which are mostly jobs that are related to the need of industry (Tesda, 2007). In addition, classes in Philippine schools start in June and end in March. Colleges and universities follow the semester calendar from June-October and November-March. However, there are a number of foreign schools with study programs similar to those of the mother country.

Philippines have a number of Chinese schools. Typically, a Chinese school is a school established explicitly for the purpose of teaching the Chinese language (of the various Chinese dialects, nowadays Standard Mandarin or Standard Cantonese are almost always the ones taught) to overseas Chinese, or to their offspring, and to the youth born in the respective countries. In some Western countries Chinese children attend Chinese school either after school (that is, elementary or middle school) on weekday afternoons, or on Saturday/Sunday mornings or afternoons. However, in the Philippines, Chinese language learning is either held mix together with the traditional subject; as an elective language program, or held during the afternoon in groups of subject like mathematics, Chinese history, Chinese language grammar, literature and speech.

Besides teaching the Chinese language, Chinese school also serves as social center which allows Chinese immigrants and their children to meet other Chinese families. However, after years of transition, Chinese schools nowadays also encounter the loss of Chinese culture brought on by cultural assimilation into the local society. Chinese schools are credited with maintaining the relatively high proportions of Chinese youth who are able to read or write Chinese, at least to a limited extent. (Spoken, as opposed to written, Chinese is likely learned as much at home as in a Chinese school).

\subsection{A concept on democratic schools}

A democratic school is a school that centers on democratic principles and participatory democracy with "full and equal" participation from both students and staff. Micua (2000) mentioned that a democratic type of school administration is governed by the following principles:

$>$ Principle of Intelligence - Only people with ability or intelligence should participate in the administration of the school. Democratic administration calls for use of intelligence rather than emotions. Often times, most school's board of trustees spent a lot of time in finding the appropriate person to become the leader of their school. A good leader should possess both the intelligence and experience in handling the day to day tasks of an administrator. In the Philippines, most cases the school board will first look inside the school community for a possible candidate rather than to outsource immediately, because they felt it is better to find someone familiar with the inner workings of the organization rather than to start fresh.

$>\quad$ Principle of Cooperation - The democratic type of school administration provides opportunity for cooperation. Group process is used in this type of school administration. Schools are made up of 
different committees in order to decide on various activities. Admission committee is use for the acceptance of new students, academic council committee for academic matters of the school, administrative council committee for administrative affairs of the school, enrollment committee for the enrollment procedure, and many others. These committees exist only when the need arises, the members are department heads, supervisors, representative from students, teachers and parents; persons who are directly involved in the task at hand or are affected by the decisions made by the committee. Cooperation and division of labor is the key in accomplishing these goals.

$>$ Principle of Participation - This type of school administration provides for individual participation and recognizes the strength or ability of each individual. Every employee has their chance to participate in the organizational process. Every sector of the organization should also have a representative in the various committees in order to voice out their opinion on matters.

$>$ Principle of Individuality - Democratic administration recognizes the uniqueness of an individual. His interests are particular interests and his abilities are special abilities. These differences are source of strength. In democratic school administration the final authority is vested in the group. Group process is utilized in formulating school policies. It is governed by the principles of cooperation rather than competition.

\section{Research methodology}

This study employed a mixed method research paradigm, wherein the researcher systematically combined or mixed ideas from both qualitative and quantitative research (Johnson \& Christensen, 2008). Mixed method design presents unique opportunities to use multiple sources of information from multiple approaches to gain new insights into the social world (Axinn, Fricke, \& Thornton, 1991). With varying data collection, researchers can provide information from one approach that was not identified in an alternative approach, at the same time, reducing non-sampling error by providing redundant information from multiple sources (Axinn \& Pearce, 2006).

Focus group interviews are among one of the most widely used qualitative research tools in the social sciences studies. A group represents a number of interacting individuals having a community of interest, and interviews means the presence of a moderator who uses the group as a device for eliciting information (Stewart \& Shamdasani, 1990). While, the term focus simply means that the interview is limited to a small number of issues (Smith, 1954). Focus groups are unique in that they openly call for respondents to interact with one another in formulating responses to interviewers' questions. A probable benefit of this approach is that interviewees may feel greater confidence in a group setting, which may encourage them to offer comments and discuss matters they wouldn't in a one-on-one interview, hence possessed a low level of structure and a medium level of researcher involvement with the study population (Axinn \& Pearce, 2006).

Surveys are used gather information at a particular point in time with the intention of describing the nature of existing conditions, or identifying standards against which existing conditions can be compared, or determining the relationships that exist between specific events (Cohen, Manion, \& Morrison, 2007). Most survey will combine nominal data on participants' backgrounds and relevant personal details with other scales (Weisberg, Kronsnick, \& Bowen, 1996). Surveys are often administered to a large number of respondents, hence, survey research are often coined to as quantitative research, which has a high level of structure and low level of researcher involvement with the study population (Axinn \& Pearce, 2006).

Mixed method design allows the different strengths and weaknesses of the information collection methods, to work in the most advantageous way for the researcher. A combination of survey methods with other less structured methods may provide the flexibility required to create new insights into the situation at hand (Axinn et al., 1991). Thus, combinations of information collection methods generate advantages that no one single method can offer (Sieber, 1973). For data analysis, the data gathered from the survey questionnaire were encoded and analyzed using the Statistics Package for Social Science (SPSS) version 15. Descriptive statistics were 
accomplished, wherein the mean, standard deviation (SD) and percentage of the respondents' selection are tabulated and analyzed. Cross-tabulations were also accomplished to compare the factors for the participants who are on scholarship with the one who are not on scholarship.

Results were than analyzed and generalized to further give insights on the existing issues at hand. For the interview results, documentation and analysis followed Stenhouse's (1985) categorization style of case data. The interviewer summarized key themes, reflections, and insights in a daily field log after each session. Minor adjustments were made for each subsequent interview based on a review of the daily field logs. Researchers independently reviewed field logs and focus group recordings to generate a list of key themes.

This study is concerned with the way in which rewards and penalties, may or may not, motivate students to engage in learning and change their behavior. The approach taken was to explore the characteristics of systems of rewards and penalties in four Chinese schools in the Philippines and students' perceptions of the effectiveness of systems currently in use. Questionnaires, observations and interviews were used to collect information about students' perceptions of rewards and penalties in their respective schools. Behind the perception that: penalties are based on fear, containment and control; rewards are linked to pedagogy and learning. This study uses the questionnaire pattern from Shreeve's (2002) study, three dimensions were also considered: engagement with learning, social comparison, and rewards and sanctions, while focusing on these specific questions:

1. Do rewards motivate students to work hard?

2. Do penalties deter students from behaving badly?

3. What do students prefer for rewards/penalties?

\section{Results and discussions}

The questionnaire was administered to four Chinese schools in the Philippines. Chinese schools in the Philippines are school who has teaches Chinese Language to students, most of the school's population came from families with Chinese ethnicity. A total of 400 hundred questionnaires were given at random to the high school 4th year (high school seniors) and college first year (freshmen) students of four schools. There are two types of schools, sectarian; wherein these schools are operated by a religious order, and non-sectarian; which are normal schools operated by either private or government. In the case of the Philippines, sectarian schools are often refers to the schools which are operated by the Roman Catholic churches or Protestant Christian churches. The survey questionnaire was returned at a voluntary basis. A total of 259 were collected, out of which 216 were considered valid returns with specific demography in table 1 . By observation the representation from students year level, school type, and gender seems to varies not more than 10\%, which is considered an acceptable sample size (Bailey, 1978). In addition, the data gathered from the survey questionnaire were encoded and analyzed using the Statistics Package for Social Science (SPSS) version 15. Internal consistency using Lee Cronbach's (1951) coefficient alpha (Cronbach's alpha) was computed at 0.69, suggesting a moderate level (Nunnally \& Bemstein, 1994).

The following results will involve in the following factors engagement with learning, social comparison, and rewards and sanctions. Table 2 shows the participants perceptions with their engagement in learning with respect to whether they know if the teacher is giving rewards or penalties. Results shows a positive view on the engagement of learning whether its rewards or penalties. Similarly it shows a correlation between the rewards and penalties when asked whether the participants will exert less during no motivation. However, an interesting result shows $45 \%$ of the student will misbehave, when they know that their teacher does not gives penalties. This would signify that during no motivation, or restrictions, students tend to disregard authority. But, in fairness, $69 \%$ of the students will still work hard regardless of whether there is positive or negative motivation in the classroom. In general, a moderate level of extrinsic motivation is better than a high level. Higher levels of intrinsic motivation are positively related to grades. Best of all is moderate extrinsic motivation coupled with 
Ching, G. S.

high intrinsic motivation. These results, like those of Covington (2000) and Pintrich (2000), indicate that extrinsic motivation is not necessarily incompatible with intrinsic motivation.

\section{Table 1}

Student participants' profile $(N=216)$

\begin{tabular}{lllllll}
\hline \multicolumn{1}{c}{ Factor } & $n$ & $\%$ & $M$ & $S D$ & Min. & Max. \\
\hline Age $^{\mathrm{a}}$ & & & 17.14 & 1.15 & 15 & 20 \\
$\quad$ Male & 101 & 47 & 17.27 & 1.18 & & \\
$\quad$ Female & 115 & 53 & 17.03 & 1.10 & & \\
Students by school type & & & & & & \\
$\quad$ Sectarian & & & & & \\
$\quad$ Non-sectarian & 102 & 47 & & & & \\
Students by level & 114 & 53 & & & \\
$\quad$ High school 4th year & 127 & 59 & & & \\
$\quad$ College first year & 89 & 41 & & & \\
\hline
\end{tabular}

Note: ${ }^{\mathrm{a}}$ Age is in years.

${ }^{b}$ Sectarian schools are schools operated by the church or any religious order.

Table 2

Student participants' perceptions regarding their engagement with learning $(N=216)^{a}$

\begin{tabular}{lrrrr}
\hline \multicolumn{1}{c}{ Factor } & Yes $(n)$ & $\%$ & No $(n)$ & $\%$ \\
\hline Do rewards make a difference? & 133 & $\mathbf{6 2}$ & 61 & 28 \\
Would you exert more on the rewarded subject? & 161 & $\mathbf{7 5}$ & 17 & 8 \\
Would you exert more on other subject? & 166 & $\mathbf{7 7}$ & 14 & 7 \\
During no rewards, will you exert less effort? & 15 & 7 & 149 & $\mathbf{6 9}$ \\
& & & \\
Do penalties make a difference? & 131 & $\mathbf{6 1}$ & 47 & 22 \\
Would you exert more on the penalized subject? & 129 & $\mathbf{6 0}$ & 38 & 17 \\
During no penalties, will you exert less effort? & 15 & 7 & 148 & $\mathbf{6 9}$ \\
During no penalties, will you misbehave? & 97 & $\mathbf{4 5}$ & 57 & 26 \\
\hline Not Par
\end{tabular}

Note: ${ }^{a}$ Participants who select 'don't know' or did not answer are not included.

Values in bold represents the higher percentage of choices.

Rewards and sanctions are likely to be effective if they are based on school principles. They are not an end in themselves and not the main means of promoting positive behavior. Their purpose relates to improving behavior for learning, with pupils achieving changes in their behavior and taking responsibility for their actions. The contradictory results of previous studies suggest the need to consider the conditions under which extrinsic motivation is detrimental to intrinsic motivation and those conditions where it is not. Barron and Harackiewicz (2001) proposed using four patterns of evidence to investigate the complexity of multiple goals for educational research.

Social comparison should be avoided. Reward giving is meant to convey competence, if not carefully offered, may encourage student to compare their own performance with that of their peers. Social comparison may possibly affect a child's developing perception of success (Shi, 2005). Similarly, excessive behaviors like aggression, noncompliance, arguing, tantrums, and disruptiveness in class make student very difficult to manage in school and often lead to their segregated educational placement. Behavioral deficits in social skills, self-management skills, and academic skills compound the difficulty for teachers, especially as these students get older (Walker et al., 1995).

Students must be given some self-determining freedom, which can be done with self-management strategies to recruit their own rewards. Students with serious behavior problems must experience some type of "educational flow experience" if they are to remain in education. This can be done with positive academic curricula that emphasize reading and success with social skills programs that actually work to help these students 
fit in with other students (Jenson, Olympia, Farley, \& Clark, 2004). Effective rewards and penalty system include the inclusion of a wide range of rewards and penalties available, with rewards outnumbering penalties as they are more effective in motivating pupils. Recognizing the behavior and not condemning the student. This would lead to a more positive acceptance of penalties (see Table 3).

Table 4 shows that more than half of the respondents know about the existence of the rewards and penalty system in the school, but this clearly not enough. In order for a rewards and penalty system to become effective, it should set clear standards and expectations that have a purpose and a role in the overall strategy agreed by the school community and communicated to everyone. Similarly, the data clearly shows that the mostly used reward types are certificates, credits or additional points, special privileges, medals and trophy, and gifts respectively. While the most frequently used penalties are giving offenses (major and minor offenses - equivalent to deduction in the conduct grades), giving consequences or punishments (constructive punishments such as copying or reciting poems, etc.), detentions (staying after class), debits (grade deduction), and oral warning (reprimand) respectively. But the data also suggest that there are quite a number of students who doesn't realize that there is a system of rewards and penalty in the school.

\section{Table 3}

Student participants' perceptions regarding social comparison $(N=216)^{a}$

\begin{tabular}{|c|c|c|}
\hline Factor & $n$ & $\%$ \\
\hline \multicolumn{3}{|l|}{ Rewards venue } \\
\hline Privately by teachers & 27 & 13 \\
\hline In front of class & 59 & 27 \\
\hline In general assembly & 103 & 48 \\
\hline \multicolumn{3}{|l|}{ Rewards frequency } \\
\hline Never & 83 & 39 \\
\hline Once a week & 3 & 1 \\
\hline More than once a week & 5 & 2 \\
\hline Once a month & 17 & 8 \\
\hline Once a term/semester & 107 & 50 \\
\hline \multicolumn{3}{|l|}{ Reasons for reward } \\
\hline To encourage you to be your best & 94 & 44 \\
\hline To get you to behave well & 15 & 7 \\
\hline To reward you for your good work & 81 & 38 \\
\hline I was never awarded & 26 & 12 \\
\hline \multicolumn{3}{|l|}{ Penalty venue } \\
\hline Privately by teachers & 49 & 23 \\
\hline In front of class & 24 & 11 \\
\hline In general assembly & 9 & 4 \\
\hline I was never penalized & 124 & 57 \\
\hline \multicolumn{3}{|l|}{ Penalty frequency } \\
\hline Never & 143 & 66 \\
\hline Once a week & 10 & 5 \\
\hline More than once a week & 3 & 1 \\
\hline Once a month & 7 & 3 \\
\hline Once a term $/$ semester & 45 & 21 \\
\hline \multicolumn{3}{|l|}{ Reasons for penalty } \\
\hline To make you work better & 70 & 33 \\
\hline To stop bad behavior & 113 & 52 \\
\hline Don't know & 33 & 15 \\
\hline
\end{tabular}

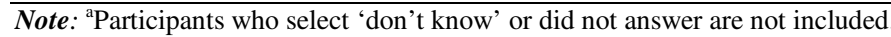

Values in bold represents the higher percentage of choices. 
Ching, G. S.

\section{Table 4}

Student participants' perceptions regarding rewards and penalties $(N=216)^{a}$

\begin{tabular}{|c|c|c|c|c|}
\hline Factor & Yes $(n)$ & $\%$ & No $(n)$ & $\%$ \\
\hline Do you have rewards? & 135 & 63 & 57 & 26 \\
\hline \multicolumn{5}{|c|}{ What do you call the reward? } \\
\hline Credit & 18 & 8 & & \\
\hline Certificates & 132 & 61 & & \\
\hline Plus points & 3 & 1 & & \\
\hline Special privileges & 10 & 5 & & \\
\hline Medals & 7 & 3 & & \\
\hline Gifts & 1 & 1 & & \\
\hline Do you have penalties? & 135 & 63 & 57 & 26 \\
\hline \multicolumn{5}{|c|}{ What do you call the penalty? } \\
\hline Point deduction & 7 & 3 & & \\
\hline Consequences & 32 & 15 & & \\
\hline Detentions & 34 & 16 & & \\
\hline Offenses & 7 & 3 & & \\
\hline
\end{tabular}

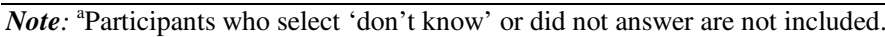

Values in bold represents the higher percentage of choices.

\section{Conclusion}

This study is concerned with the way in which rewards and penalties, may or may not, motivate students to engage in learning and change their behavior. The approach taken was to explore the characteristics of systems of rewards and penalties in four Chinese schools in the Philippines and students' perceptions of the effectiveness of systems currently in use. Results showed that although school policies tended to link their rewards and penalties system with a positive discipline approach the emphasis in practice often appeared to be on penalties for bad behavior rather than enhancing engagement and motivation. Students tended to perceive rewards to be strongly linked to work and penalties to behavior. Further in-depth analysis is urged to better understand the difference in school types and students level (high school seniors/college freshmen).

NOTE: An early version of this paper is presented at the 2009 Annual Conference of the Comparative Education Society of Hong Kong. 


\section{References:}

Atkinson, J. (1957). The motivational determinants of risk-taking behavior. Psychological Review, 64, 357-372. $<$ http://dx.doi.org/10.1037/h0043445>

Axinn, W. G., Fricke, T. E., \& Thornton, A. (1991). The micro demographic community-study approach: Improving survey data by integrating the ethnographic method. Sociological Methods and Research, 20(2), 187-217. <http://dx.doi.org/10.1177/0049124191020002001>

Axinn, W. G., \& Pearce, L. D. (2006). Mixed method data collection strategies. New York: Cambridge University Press.

Bailey, K. D. (1978). Methods of social research. Basingstoke: Collier-Macmillan.

Barron, K. E., \& Harackiewicz, J. M. (2001). Achievement goals and optimal motivation: Testing multiple goal models. Journal of Personality and Social Psychology, 80, 706-722.

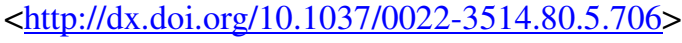

Beresford, J. (2000, September 7-10). Student perspectives on school improvement. Paper presented at the British Educational Research Association Conference, Cardiff University.

Boekaerts, M. (2002). Motivation to learn. Brussels, Belgium: International Academy of Education.

Burnett, P. C. (2002). Teacher praise and feedback and students' perceptions of the classroom environment. Educational Psychology, 22(1), 5-16. <http://dx.doi.org/10.1080/01443410120101215>

Cameron, J. (2001). Negative effects of rewards on intrinsic motivation - A limited phenomenon: Comment on Deci, Koestner, and Ryan - 2001. Review of Educational Research, 71(1), 29-42. <http://dx.doi.org/10.3102/00346543071001029>

Chan, Z., \& Ma, J. (2004). Daughter praising, mother bashing: A case study from Hong Kong. Health Care For Women International, 25(2), 195-207. <http://dx.doi.org/10.1080/07399330490267459>

Ched. (2007). Commission on higher education. Retrieved December 2, 2007, from http://www.ched.gov.ph/

Cohen, L., Manion, L., \& Morrison, K. (2007). Research methods in education. New York: Routledge.

Covington, M. V. (2000). Goal theory, motivation, and school achievement: An interactive review. Annual Review of Psychology, 171-198. <http://dx.doi.org/10.1146/annurev.psych.51.1.171>

Cronbach, L. J. (1951). Coefficient alpha and the internal structure of tests. Psychometrika, 16, 197-334. $<$ http://dx.doi.org/10.1007/BF02310555>

Deci, E. L., Koestner, R., \& Ryan, R. M. (2001). Extrinsic rewards and intrinsic motivation in education: Reconsidered once again. Review of Educational Research, 71(1), 1-27. http://dx.doi.org/10.3102/00346543071001001

DepEd. (2007a). Department of education. Retrieved December 2, 2007, from http://www.deped.gov.ph/

DepEd. (2007b). Fact sheet - Basic education statistics. Retrieved December 1, 2007, from http://www.deped.gov.ph/cpanel/uploads/issuanceImg/factsheet2007(Aug31).pdf

Jenson, W. R., Olympia, D., Farley, M., \& Clark, E. (2004). Positive psychology and externalizing students in a sea of negativity. Psychology in the Schools, 41(1), 67-79. <http://dx.doi.org/10.1002/pits.10139>

Johnson, B., \& Christensen, L. (2008). Educational research - Quantitative, qualitative, and mixed approaches (3rd ed.). Thousand Oaks, California: Sage Publications.

Kohn, A. (1994). The risk of rewards. Retrieved July 30, 2008, from http://www.alfiekohn.org/teaching/pdf/The\%20Risks\%20of\%20Rewards.pdf

McClelland, D. (1958). Risk taking in children with high and low need for achievement. In J. Atkinson (Ed.), Motives in fantasy, action and society (pp. 306-339). Princeton: Van Nostrand.

McClelland, D., Atkinson, J., Clark, R., \& Lowell, E. (1976). The achievement motive (2nd ed.). Hoboken, NJ: John Wiley \& Sons Inc.

McWhaw, K., \& Abrami, P. C. (2001). Student goal orientation and interest: Effects on students' use of self-regulated learning strategies. Contemporary Educational Psychology, 26, 311-329. $<$ http://dx.doi.org/10.1006/ceps.2000.1054>

Micua, T. S. (2000). Administration, supervision and the academic leaders. Manila: CKS.

Nunnally, J. C., \& Bemstein, L. H. (1994). Psychometric theory. New York: McGraw-Hill.

Pintrich, P. R. (2000). Multiple goals, multiple pathways: The role of goal orientation in learning and achievement. Journal of Educational Psychology, 92(3), 544-555. $<$ http://dx.doi.org/10.1037/0022-0663.92.3.544>

Shi, L. X. (2005). On becoming an effective praiser. Retrieved July 29, 2008, from http://serendip.brynmawr.edu/sci_edu/edtech04/expanding/ed225s05/lim.html

Shreeve, A., Boddington, D., Bernard, B., Brown, K., Clarke, K., Dean, L., et al. (2002). Student perceptions of 
rewards and sanctions. Pedagogy, Culture and Society, 10(2), 239-256.

<http://dx.doi.org/10.1080/14681360200200142>

Sieber, S. D. (1973). The integration of fieldwork and survey methods. American Journal of Sociology, 78(6), 1335-1359. <http://dx.doi.org/10.1086/225467>

Smith, G. H. (1954). Motivation research in advertising and marketing. New York: McGrawHill.

Stenhouse, L. (1985). Research as a basis for teaching. London, UK: Heinemann.

Stewart, D. W., \& Shamdasani, P. N. (1990). Focus groups - Theory and practice. Newbury Park, California: Sage Publications.

Tesda. (2007). Technology education and skills development authority. Retrieved December 2, 2007, from http://www.tesda.gov.ph/

Walker, H. M., Colvin, G., \& Ramsey, E. (1995). Anti-social behavior in school: Strategies and best practices. Pacific Grove, CA: Brooks/Cole Publishing.

Weisberg, H. F., Kronsnick, J. A., \& Bowen, B. D. (1996). An introduction to survey research, polling, and data analysis (3rd ed.). Thousand Oaks, CA: Sage. 